\title{
PALEOLÍTICO MEDIO EN NAVARRA, NUEVOS DATOS PARA UNA SÍNTESIS
}

THE MIDDLE PALAEOLITHIC IN NAVARRA. NEW EVIDENCE FOR A SYNTHESIS

por

\author{
Mª AMOR BEGUIRISTAIN GÚRPIDE
}

RESUMEN Se dan a conocer trece lugares inéditos, todos ellos al aire libre, que han proporcionado materiales líticos con presencia de técnica levallois y útiles muy característicos de los horizontes musterienses. Se cataloga, en una visión de conjunto, la totalidad de yacimientos navarros, hasta la fecha conocidos, atribuidos al Paleolítico Medio.

\begin{abstract}
Thirteen new archaeological sites, all of them in open air places, are introduced in this paper. They evidense lithic materials with the technique levallois and other typical artifacts of the mousterian period. All the navarrese sites attached to the middle palaeolithic and knowed up to this day, are presented.
\end{abstract}

Palabras claves Paleolítico Medio. Valle del Ebro-Navarra. Nuevos yacimientos.

Key words Middle Palaeolithic. Ebro-Valley. Newsites

\section{PRESENTACIÓN}

En la más reciente síntesis sobre Paleolítico Medio de la Península Ibérica llama la atención la carencia de datos referidos a Navarra ${ }^{1}$. Es mi intención, en esta oportunidad que la Universidad de Sevilla me brinda de escribir con ocasión del homenaje al que fue mi maestro, el querido Profesor Vallespí, paliar ese vacío reuniendo, junto a los datos ya conocidos, otros inéditos descubiertos en la última década. Creo que es un modo de contribuir a la síntesis solicitada, haciendo justicia al destinatario del merecido homenaje, ya que fue el primero en dar a conocer la existencia de industrias musterienses en este pequeño territorio del Valle del Ebro.

1. Me refiero a la síntesis de Vega, Raposo y Santonja (1999: 23-48). 
Debo agradecer a mi colega Jesús García Gazólaz el haber puesto a mi disposición unos materiales que custodiaba, algunos desde hacía bastantes años, descubiertos, en su mayor parte, por él mismo.

No sería necesario repetir el catálogo de yacimientos atribuidos al Paleolítico Medio de Navarra dadas las publicaciones que en los últimos años han visto la luz, tanto desde la propia Universidad de Navarra ${ }^{2}$ como desde la de Zaragoza ${ }^{3}$. Sin embargo, publicaciones posteriores a dichas síntesis y recientes descubrimientos totalmente inéditos, que parecen reforzar la presencia de musterienses en Navarra, nos han animado a recopilarlos en su totalidad para facilitar el acceso a $\operatorname{los}_{\operatorname{mismos}}{ }^{4}$ (Figura 1).

\section{ORDENACIÓN ALFABÉTICA DE YACIMIENTOS}

Abauntz (Arraiz, Valle de Ulzama). Yacimiento en cueva en la vertiente meridional de los montes de Velate, línea divisoria entre las cuencas hidrográficas mediterránea y atlántica, abre su boca en una ladera de la margen derecha del río Ulzama. Fue explorada y descubierta por Telesforo de Aranzadi y José Miguel de Barandiarán (1934), ha sido objeto de excavaciones dirigidas por Pilar Utrilla desde 1976 y desde 1991 en codirección con Carlos Mazo. Conocida por sus interesantes series referidas a etapas holocénicas y al Paleolítico Superior, ha dado una nueva sorpresa con la confirmación, bajo nivel grueso de arcillas, de un nivel referido al Würm antiguo con hendedores, bifaces, raederas, alguna punta, y denticulados entre otros materiales líticos asociados a fauna de oso, lobo, conejo, ciervo, cabra y uro, según una apreciación inicial de sus excavadores (Mazo y Utrilla 1995-1996: 273-274).

Arazuri 1 (Cuenca de Pamplona). (Material inédito). De este lugar, conocido por sus materiales del Paleolítico Inferior (Castiella et alii 1999*: 258), proceden dos piezas atribuibles al musteriense. Se trata de una lasca laminar levallois con muesca, en sílex con marcada pátina que le confiere un color amarillento, sobre materia prima del "tipo Urbasa". La segunda pieza es un núcleo levallois agotado, sobre sílex negro "tipo Olabe". Ambas piezas se encontraron en posición derivada dentro de una de las terrazas del Arga.

Balsa de Aranzaduia (Sierra de Urbasa). Yacimiento al aire libre, en el Raso de la Sierra de Urbasa, descubierto y prospectado en sucesivas ocasiones por Emilio Redondo desde 1968. De este lugar publicó Enrique Vallespí las primeras noticias (Vallespí 1971: 565-583). En las sucesivas síntesis se repiten los datos de esta primera caracterización, con excepción de la inclusión de algún hendedor recuperado con posterioridad a esa fecha (Barandiarán y Vallespí 1984: 81 y fig. 45).

Bioiza (Sierra de Urbasa). Cantera al aire libre descubierta y prospectada por Emilio Redondo en 1974, con material de taller y piezas de tipología inferopaleolítica y del Paleolítico Medio. La única referencia bibliográfica de este lugar-denominado en la catalogación de Barandiarán y Cava "URB.14"-se encuentra en Barandiarán y Montes (1991-1992: 48).

Canteras de Alaiz (Cuenca de Pamplona, Tiebas). (Material inédito). De procedencia imprecisa dentro de la explotación de calizas de la Sierra de Alaiz, se conoce una pieza denticulada en sílex con fuerte pátina

\footnotetext{
2. I. Barandiarán (1995), "Los establecimientos..." CAUNA 3: 53-84.

3. L. Montes (1998), El Musteriense en la Cuenca del Ebro, Zaragoza.

4. C. Mazo y P. Utrilla (1995-1996): "Excavaciones en la cueva de Abauntz (Arraiz). Campañas de 1994 y 1995”, TAN 12: 273-274.
} 
melada, sin otra referencia, ya que fue recogida, por la firmante de este escrito, entre las calizas trituradas que para arreglar los caminos se habían llevado al pueblo de Obanos desde dicho lugar.

Coscobilo (Olazagutía). Yacimiento destruido por las canteras de cemento allí ubicadas. Se trataba de una cueva sin duda de enorme importancia por su proximidad a la Sierra de Urbasa, en el corazón del corredor de la Barranca, excavado por el próximo río Araquil, afluente del Arga ${ }^{5}$. La posibilidad de que en su base hubiera un musteriense la apuntó Enrique Vallespí en 1971 al dar a conocer piezas de la colección Ruiz de Gaona ${ }^{6}$. El estudio de la Colección Barandiarán, realizado sobre materiales recuperados en la escombrera, confirmó su atribución al Paleolítico Medio y a diversas facies del Superior ${ }^{7}$.

Eriete 1 (Cuenca de Pamplona). (Material inédito). En el paraje conocido como "Viñas Viejas", sobre el tercer nivel de terrazas del río Arga, se localizaron materiales holocénicos (Castiella et alii 1999*: 91). Además, una única pieza, un buril sobre soporte nucleiforme de avivado, con pátina claramente pre-holocénica, en sílex "tipo Olabe”.

Fuente de Aciarri (Sierra de Urbasa). Descubierto por Emilio Redondo, la referencia a la pertenencia al musteriense de un lote de piezas allí recuperadas se debe a Barandiarán y Vallespí (1984: 82), a Barandiarán y Montes (1991-92: 51) y a Barandiarán (1995: 59-60) “con reservas" en esta última cita.

Fuente de Andasarri (Sierra de Urbasa). Descubierto y prospectado por Emilio Redondo, se han dado a conocer materiales que parecen indicar la existencia de un área de taller en este paraje (Tabar 1975: 82-84 y 1978: 5-33; Barandiarán y Vallespí 1984: 81-82; Barandiarán y Montes 1991-92: 50; Barandiarán 1995: 60). Se ubica junto a un punto de agua, en la zona central del sinclinal colgado que es esta Sierra caliza de Urbasa, lo que hace pensar que en el Würm, como en la actualidad, uno de los mayores atractivos para la elección del lugar pudo ser el disponer de agua, dadas las características permeables de estos suelos.

Fuente de Gorlasaro (Sierra de Urbasa). Referencias a este lugar, donde Emilio Redondo descubrió un lote lítico atribuido al Musteriense, se encuentran en Barandiarán y Montes (1991-92: 49), y Barandiarán (1995: 60). Al igual que otros asentamientos de esta sierra cárstica, los materiales se recogieron en las proximidades de un punto de agua.

Galar 1 (Cuenca de Pamplona). (Material inédito). Materiales recogidos por García Gazólaz en el frente de un glacis de erosión de la vecina sierra del Perdón. El lugar se conoce por el asentamiento atribuido al Calcolítico sobre "suelo margoso" con abundantes cantos (Castiella et alii 1999*: 227). Las piezas que nos interesan son dos: una lasca denticulada en sílex muy bueno, exógeno; y un núcleo agotado de tecnología levallois, en sílex local "tipo Perdón". El córtex rebasa los lascados y presenta dos frentes opuestos de raedera.

Gazólaz 4 (Cuenca de Pamplona). (Material inédito). En el paraje conocido como "Iticulanes I", sobre una terraza de la margen izquierda del Arga, recogió García Gazólaz un núcleo levallois agotado, sobre sílex local "tipo Perdón"; una raedera lateral inversa, denticulada, en lasca laminar, y una tercera pieza denticulada en el mismo tipo de soporte, de sílex "tipo Urbasa".

5. Un resumen de las circunstancias que rodearon el descubrimiento de este polémico yacimiento se puede ver en Beguiristain (1974)

6. Vallespí y Ruiz de Gaona (1971).

7. Vid. Nota 5. 
Ibero 3 (Cuenca de Pamplona). (Material inédito). Paraje conocido como "Paternainbidea I" ("camino de Paternain"), del que se han dado a conocer materiales atribuidos al Paleolítico Inferior (García Gazólaz 1994: 17; Beguiristain 1995: 40; y Castiella et alii 1999*: 266), procede alguna pieza de tecnología musteriense. Destaca una pieza bifacial con retalla en uno de sus bordes y talón reservado (Figura 3 ). La pieza muestra un fuerte color melado y bordes redondeados fruto de pátina intensa.

Ibero 4 (Cuenca de Pamplona). Paraje conocido como "Paternainbidea II", que se localiza, como el anterior, en la tercera terraza del río Arga, cerca de su confluencia con el Araquil, río que desagua en la Cuenca de Pamplona tras atravesar el valle de la Barranca, entre las sierras de Urbasa y Aralar. El lugar es conocido por sus asentamientos del Neolítico y Calcolítico (García Gazólaz 1995: 106) y se hace referencia a dos momentos, el más antiguo en sílex de tonos ocres: "El tipo de utillaje asociado a éste: raederas, muescas, denticulados, etc., nos lleva a situarlo en un momento impreciso del Paleolítico Medio" (Castiella et alii 1999a: 267). En la Figura 4, se representan dos raederas dobles, una de ellas de dorso adelgazado, procedentes de esta prospección. La mayor parte de las piezas están elaboradas en sílex "tipo Urbasa" (14), algunas con pátina melada. En menor número se ha utilizado sílex "tipo Perdón” (7) y “tipo Olabe”(4). Hay alguna pieza para la que se ha empleado sílex local, procedente sin duda de pequeños nódulos de las terrazas.

Ibero 5 (Cuenca de Pamplona). (Material inédito). En la misma tercera terraza de río Arga orientada al SE-NO, en el paraje denominado "Paternainbidea III", se han recuperado casi un centenar de piezas líticas, fundamentalmente en sílex, de tecnología propia del Paleolítico Medio. El lugar había sido dado a conocer por sus materiales holocénicos, especialmente del Neolítico Pleno (Castiella et alii1999*: 268). Entre el material atribuido por nosotros al musteriense cabe destacar: 6 lascas completas; 4 núcleos de tecnología levallois agotados, uno de láminas; 2 fragmentos de lascas levallois; 1 punta levallois retocada (Figura $4 \mathrm{n}^{\circ} 3$ ); 23 raederas (Figuras 4 y 6) con los siguientes subtipos: -8 simples, laterales y transversales en la misma proporción; -las restantes dobles, entre ellas algunos tipos especiales, alguna tipo Quina, otra de dorso adelgazado (Figura $6 \mathrm{n}^{\circ}$ 1) y otra de retoque abrupto; 6 muescas, dos sobre soporte levallois; 21 denticulados en materiales y soportes muy heterogéneos; 3 raspadores sobre lasca espesa; 1 perforador y 2 lascas retocadas pedunculadas. El sílex "tipo Urbasa" parece ser el preferido en Ibero (36), pero también se usa el "tipo Olabe" (28) y el "tipo Perdón". Hay tres piezas con una intensa pátina melada oscura, pulidas por la acción erosiva del viento.

Ibero 8 (Cuenca de Pamplona). (Material inédito). Materiales de clara atribución al Paleolítico Medio, recuperados en el paraje conocido como "Antxellua". Se encuentra cerca de "Izábal II", asentamiento del Neolítico-Calcolítico ya conocido por sus cuantiosas series líticas holocénicas (Castiella et alii 1999*: 271). Ambos conjuntos proceden de la tercera terraza del Arga, a unos $900 \mathrm{~m}$ sobre el nivel del cauce actual. Del lugar procede un pequeño lote de treinta piezas sobre lasca de cuarcita y sílex de calidades, éstos últimos, muy diversas cuyo denominador común es una pátina amarillenta, algunos con señal de rodamiento postdeposicional y brillo característico. Las cuarcitas aparecen menos rodadas, algunas conservan parte de la estructura del canto utilizado en su elaboración. Entre los tipos identificados cabe señalar: 7 núcleos pequeños con extracciones centrípetas, algunos claramente "en tortuga" (Figura $7 \mathrm{n}^{\circ} 1-3$ ); 3 raederas simples, otra bifacial y otra con epí opuesta al borde de raedera; 5 denticulados; 1 raclette; 1 raspador sobre lámina retocada; y 11 lascas, algunas laminares de tecnología levallois, sin retoques intencionados. También aquí predomina el sílex "tipo Urbasa" frente a las otras modalidades.

Mugarduia Norte (Sierra de Urbasa). Inicialmente publicado por error como "Otxaportillo" (Tabar 1975: 79-81 y 1977: 371-402), fue descubierto por Emilio Redondo junto a la mayor parte de las localizaciones 
de esta Sierra. Un sondeo estratigráfico dirigido por Barandiarán en 1982 concretó la existencia de un importante taller de sílex (Barandiarán y Montes 1992: 47). Junto a los restos de talla se recuperaron piezas retocadas que en opinión de Barandiarán encajan en el Musteriense típico o en el Musteriense de tradición achelense (Barandiarán 1995: 61 y 65). Para Montes los instrumentos retocados en este taller, donde se han tallado nódulos de sílex local (casi 40.000 restos líticos recuperados), se deben clasificar en un musteriense, en el que, como indicaron sus excavadores, subyace una tradición achelense, que se manifiesta principalmente en los bifaces y hendedores. No obstante, dicha autora considera la presencia de raederas bifaciales tipo hachoir, muy características de la facies Quina, llevándole a afirmar: "Creemos que en realidad, la Sierra de Urbasa fue visitada por el hombre de Neandertal buscando su riqueza de sílex, por lo que no podemos circunscribir los restos musterienses sólo a una facies" (1988: 164).

Olabe (Valle de Ulzama). (Material inédito). En terrazas del río Arga, recogió hace años García Gazólaz un pequeño lote de piezas de sílex. El lugar resulta muy interesante por diversas razones. Al interés intrínseco de la tipología musteriense de los materiales, se añade el de su proximidad a afloraciones con sílex de buena calidad que aparece en nódulos dentro de afloramientos cretácicos. Un valor añadido es el de su ubicación, ya que Olabe se encuentra a orillas del río Ulzama, afluente del Arga, está, por tanto, entre la ya citada cueva de Abauntz, en el curso alto de éste río y la Cuenca de Pamplona. Los materiales analizados son: 4 núcleos levallois, alguno tal vez discoide; una lasca levallois con pico aburinado; 4 raederas, dos de ellas sobre lasca kombewa; un cuchillo sobre dorso natural; 1 cuchillo de dorso natural; 1 muesca; 7 denticulados; 1 punta de Tayac, además de un lote de láminas y núcleos con extracciones laminares y pátina más reciente, tratándose, como los anteriores, de materiales encontrados al aire libre. De todo el lote, sólo una lasca laminar está retocada sobre sílex del "tipo Urbasa", el resto es materia prima local de la que venimos denominando "tipo Olabe".

Ororbia 2 (Cuenca de Pamplona). (Material inédito). Del lugar denominado "Mamantías" y conocido por un asentamiento atribuido al Neolítico y Calcolítico (Castiella et alii 1999*: 287), se conservan en el Museo de Navarra: -una lasca laminar de talón liso natural, que muestra talla centrípeta en una de las caras y retoque abrupto en un borde, mientras que en el opuesto tiene una muesca; y -una lasca cortical de modo 1 con retoque Simple en todos sus bordes, completado uno de ellos por retoque inverso. La pieza es una raedera bifacial.

Ororbia 3 (Cuenca de Pamplona). (Material inédito). En los mismos fondos del Museo de Navarra se conserva una raedera lateral, con pátina fuertemente melada y desconchados naturales por su posición secundaria dentro de la segunda terraza del Arga. El topónimo concreto en que se recuperó se denomina "San Cristóbal II" (Castiella et alii 1999*: 288).

Pozo Laberri (Sierra de Urbasa). Descubierto por Emilio Redondo, el lugar, con algo más de "una docena larga de piezas talladas referibles, con bastante probabilidad, al Paleolítico medio" (Barandiarán 1995: 63), ha sido citado en diversos trabajos de síntesis (Barandiarán y Vallespí 1984: 82; Barandiarán y Montes 1991-92: 47-50).

Pozo Negro (Urbasa). Este lugar también fue localizado por Redondo y con las mismas referencias bibliográficas que "Pozo Laberri". Su caracterización se debe a una treintena de piezas recogidas por su descubridor. Es típico su emplazamiento próximo a un punto de agua, condicionado por las características cársticas de esta sierra, en la que la carencia de agua limita los establecimientos permanentes y numerosos. 
Salinas 1 (Cuenca de Pamplona). (Material inédito). Yacimiento al aire libre sobre la terraza fluvial de $517 \mathrm{~m}$ s.n.m., que forma el cerro de Allomendi. El lugar se conocía por la existencia de un asentamiento de la Edad del Hierro en la cumbre y materiales líticos holocénicos ${ }^{8}$. De éste paraje procede un lote de 94 piezas líticas recogidas, en prospecciones diferentes, por Jesús García Gazólaz y Joseba López de Haro. El análisis tecno-tipológico de los materiales que ahora se analizan permite su atribución al musteriense. Las materias primas utilizadas proceden, en su mayor parte, de sílex local originario de la vecina Sierra del Perdón, de calidad mediocre (42). También se han utilizado pequeños nódulos que muestran superficies redondeadas fruto de un intenso rodamiento (39). No faltan cuarcitas y otras rocas metamórficas que pueden proceder de los conglomerados de la vecina sierra del Perdón o de arrastres del río Arga, ni tampoco algunas piezas en sílex "tipo Urbasa" (9) y "Olabe (8). Es llamativa una pieza ejecutada sobre canto rodado muy plano, de roca tenaz dura y de grano muy fino, en color negro, al parecer lutita, material presente tanto en las calizas como en las areniscas de la Zona Media de Navarra atravesada por el Arga en su curso mediobajo. Doce son las cuarcitas retocadas recuperadas en Salinas 1. El análisis de la industria nos indica la siguiente distribución tipológica:

-Entre los restos de taller (22): restos nucleiformes con pseudo denticulaciones (6), lascas de ancho talón liso, frecuentemente cortical (12), una lasca de cuarcita con talón facetado y tres lascas laminares con talones eliminados. -Además hay un núcleo levallois de láminas, reutilizado (Figura 2 superior). -Entre las piezas tipológicas (54): lasca levallois grande en cuarcita (1), punta levallois retocada (1, pequeña), raederas (21) [7 laterales simples rectas, 7 simples convexas, una cóncava, 2 transversales convexas, una cóncava, una convergente y dos latero-transversales convexas], raspadores sobre soporte grueso (7), un cuchillo de dorso, muescas (8) [6 verdaderas y 2 clactonienses ], denticulados (23) sobre soportes heterogéneos, una punta de Tayac, picos aburinados (2), una punta foliácea bifacial, un buril, un chopping tool o canto bifacial en basalto, cinco diversos, y un triedro sobre canto rodado muy aplanado con incisiones muy finas en la zona cortical, en lutita (i) (Figura 2 inferior), de difícil clasificación. El tipo dominante es la raedera y está muy presente la técnica levallois.

Tudela, alrededores (Ribera del Ebro). Pilar Utrilla apunta la posibilidad de que algunos materiales recogidos en este término municipal sean del Paleolítico Inferior o Medio (Utrilla 1984: 11-23, y Montes 1988: 166). Prospecciones llevadas a cabo en la Ribera de Navarra por miembros del Departamento de Historia de la UN, por encargo del Museo de Navarra con fines patrimoniales, han confirmado la existencia de lotes de marcado aire musteriense, y del Paleolítico inferior, en terrazas del Ebro y cerros con afloramiento de sílex. Esta información, de momento confidencial, refuerza la idea de Utrilla.

Viana (Ribera del Ebro). En el paraje denominado "Matamala", en la tercera terraza del Ebro, se recuperó un lote de cincuenta y ocho piezas en cuarcita, que en opinión de Susana Irigaray se deben adscribir "a partir del Achelense Medio en adelante". Esta autora sugiere, ante la abundancia de piezas corticales, un desbaste "in situ" (1992: 79).

Varios. Recientemente se han atribuido al "Achelense Superior-Final o incluso al Musteriense"... "la mayor parte de los yacimientos estudiados... y bifaces aislados" que se han publicado en diferentes ámbitos (Armendáriz 1997-98: 354 y 356).

8. A. Castiella (1991-1992): "Informe de los trabajos arqueológicos realizados en los yacimientos de Allomendi (Salinas) y Machamendi (Ubani)”, en TAN 10: 421-422. Más detalles en: A. Castiella et alii (1999). 


\section{VALORACIÓN DE LOS DATOS}

Llegados a este punto cabe preguntarse por el interés que tiene la recopilación de yacimientos descritos con anterioridad y el dar a conocer estos trece nuevos puntos, que en su mayor parte han proporcionado reducidos materiales, procedentes de posiciones secundarias y derivadas, sin argumentos estratigráficos. Consciente del escepticismo que causan entre los prehistoriadores los estudios exclusivamente tecnotipológicos, he evitado hacer una descripción exhaustiva, haciendo tan sólo una valoración tipológica mínima y la anotación de aquellos caracteres técnicos más significativos a favor de la atribución musteriense de las industrias. En los conjuntos antes descritos, llama la atención la relativa abundancia de núcleos de técnica levallois, preferentemente de lascas, con frecuentes reaprovechamientos que llevan a convertir estos núcleos tipo "tortuga" en útiles. Las raederas constituyen el tipo más numeroso y variado. En el aspecto tipométrico, predominan los elementos medianos y pequeños, siendo entre los lotes analizados verdadera excepción las piezas grandes o muy grandes, según las pautas tipométricas de Bagollini.

Lo que también resulta evidente, a la vista del mapa de la Figura 1, es la estrecha relación entre prospección y localización, ya que los materiales se concentran en dos zonas netas: una, la clásica área de Urbasa, en la zona occidental de Navarra y la segunda se localiza en la Cuenca de Pamplona, comarca con una personalidad geográfica bien definida. Ambas zonas, por circunstancias diversas, han sido objeto de intensas prospecciones ${ }^{9}$.

A cada una de estas áreas le corresponde una gran cueva próxima: Coscobilo de Olazagutía $\left(n^{\circ} 6\right)$ se ha relacionado con Urbasa (Ruiz de Gaona, Barandiarán...), y Abauntz $\left(\mathrm{n}^{\circ} 1\right)$ puede vincularse sin demasiados esfuerzos con el foco de la Cuenca de Pamplona contando con el enlace de Olabe ( $\left.n^{\circ} 18\right)$, en el mismo valle de la Ulzama, zona rica en nódulos de un sílex negro, de buena calidad, utilizado tanto por los ocupantes de la Cuenca de Pamplona como en Abauntz.

Creo que será precisamente la materia prima empleada uno de los aspectos que con estudios adecuados puede dar luz acerca de los hábitos y relaciones entre los grupos de Neandertales que pudieron ocupar este territorio. Hemos constatado, en este sentido, la presencia en la Cuenca de Pamplona de sílex "tipo Urbasa", en proporciones importantes. Precisamente, los yacimientos con más presencia de este tipo de sílex se encuentran próximos a la confluencia del Arga y el Araquil, río que atraviesa el corredor de la Barranca pasando ante la destruida cueva de Coscobilo. Son los yacimientos catalogados como Ibero 3, 4, 5 y 8 (n ${ }^{\circ}$ s. 13 a 16). Desde la Cuenca de Pamplona, hace falta menos de un día para llegar a pie hasta la Sierra de Andía, que es la prolongación de Urbasa hacia el Este, y en donde el sílex es también abundante. También los ocupantes de la Cuenca utilizaron el excelente sílex de Olabe y en menor proporción el sílex mediocre de la vecina Sierra del Perdón, que cierra la Cuenca por el Sur. Cabe destacar una excepción, la del emplazamiento llamado "Machamendi", catalogado como Salinas 1 (n²3), donde se hizo un empleo exhaustivo de pequeños nódulos de sílex procedente de terrazas y de la Sierra del Perdón, en ambos casos, muy mediocre.

9. Como han indicado repetidas veces tanto E. Vallespí como I. Barandiarán, el descubrimiento de la red de estaciones de esta Sierra de Urbasa se debe a la incesante labor de búsqueda llevada a cabo durante muchos años por Emilio Redondo, vecino que fue de Zudaire, quien puso a disposición de los investigadores citados todos sus materiales con ejemplar generosidad. La información de yacimientos paleolíticos de la Cuenca de Pamplona se debe también a otro prospector, J.M. Martínez Txoperena, quien a lo largo de 1993 prospectó esta comarca localizando numerosos asentamientos de diversas épocas que entregó para su estudio al licenciado Jesús García Gazólaz. Este último, empezó a prospectar aquellas zonas de terrazas antiguas y glacis en los que pudiera aparecer material Infero-Paleolítico, recogiendo a la par materiales de tecnología más reciente (García Gazólaz 1994: 15). Estaba ya gestándose por esas fechas un proyecto de estudio arqueológico de toda la Cuenca de Pamplona que duró tres años (1994-1996), con prospecciones intensivas de cobertura total, bajo la dirección de mi colega del Departamento de Historia de la Universidad de Navarra, Amparo Castiella. Como resultado del mismo se han publicado dos tomos en 1999, en la revista CAUNA, que han sido citados a lo largo de estas páginas. En ellos se explica el método y resultados. Por tanto, las condiciones que rodearon estas prospecciones son una garantía de cómo se recuperaron estos materiales. 
Vuelvo a repetir que no ignoro las limitaciones que impone la ausencia de estratigrafías que acompañen y refuercen los datos aportados. El Paleolítico Medio en Navarra está reclamando estudios específicos avalados por equipos interdisciplinares, que aborden la presencia del hombre de Neandertal en estas latitudes. El medio geofísico de Navarra carece de razones objetivas para un vacío ocupacional durante el Würm antiguo. Caza, agua, conjuntos cársticos y materias primas están ampliamente presentes en este territorio del Valle del Ebro. No dudo en afirmar que la escasez de información obedece a carencias de investigaciones por falta de tradición para abordar las etapas iniciales de la Prehistoria, en una región volcada al estudio de sus estadios más recientes, especialmente de fenómenos como el megalitismo, la indoeuropeización y la romanización.

Para el Paleolítico Medio disponemos de millares de piezas procedentes de un yacimiento, Coscobilo de Olazagutía, destruido por una cantera de explotación industrial de las calizas, explotación que genera numerosos puestos de trabajo. El estudio de otras probables cuevas que hubieran podido aparecer en esta zona calcárea está totalmente vedado. Por tanto, la única cueva con una estratigrafía que parece importante es Abauntz y su conservación también peligra, ya que parece estar en vías de desaparición bajo las aguas de un futuro embalse. Paradójicamente, habrá presupuesto para excavarla si se materializa el embalse que la anegará. El resto de la información, con la honrosa excepción de Mugarduia Norte, procede de recogida de materiales de superficie, bien en el sinclinal colgado que es la sierra de Urbasa, bien en terrazas fluviales o en glacis muy modificados, tanto por agentes naturales como por la acción antrópica. Esta es la realidad que tenemos. Pese a tales limitaciones, incluso debido a ellas, considero importante dar a conocer los nuevos datos de esta zona del Valle del Ebro, como estímulo para investigaciones futuras que deberían emprenderse en el marco de programas interdisciplinares. 


\section{BIBLIOGRAFÍA}

SIGLAS de revistas:

CAUNA: Cuadernos de Arqueología de la Universidad de Navarra

$P V$ : Príncipe de Viana

TAN: Trabajos de Arqueología Navarra

ARMENDÁRIZ, J. (1997-1998): "Hallazgo de dos nuevos bifaces paleolíticos en el valle del río Ega", TAN 13: 349-357.

BARANDIARÁN, I. (1995): "Los establecimientos de cazadores de la Prehistoria de Navarra. Del Paleolítico Medio a inicios del Neolítico", CAUNA 3: 53-84.

BARANDIARÁN, I. y MONTES, L. (1991-1992): “ Ocupaciones del Paleolítico en Urbasa (Navarra), el sitio de Mugarduia Norte", TAN 10: 21-67.

BARANDIARÁN, I. y VALLESPÍ, E. (1984): "La Prehistoria de Navarra", TAN 2 (monográfico).

BEGUIRISTAIN, Ma A. (1974): "La colección Barandiarán de Coscobilo de Olazagutía", PV 136-137: 345-401.

CASTIELLA, A.; SESMA, J.; GARCÍA, M.L.; GARCÍA, J.; PRIETO, J.J.; FARO, J.A. y GARCÍA, D. (1999): "Poblamiento y territorialidad en la Cuenca de Pamplona: Una visión arqueológica", TAN 7 (2 vols. monográficos).

GARCÍA GAZÓLAZ, J. (1995): "Apuntes para la comprensión de la dinámica de ocupación del actual territorio navarro entre el VI y el III milenio", CAUNA 3: 85-146.

IRIGARAY, S. (1992): "Estudio del yacimiento de Matamala: los materiales paleolíticos y la industria holocena", II Congreso General de Historia de Navarra, PV anejo 14: 75-86.

MAZO, C. y UTRILLA, P. (1995-1996): "Excavaciones en la cueva de Abauntz (Arraiz). Campañas de 1994 y 1995", TAN 12: 270-279.

MONTES, L. (1988): El Musteriense en la Cuenca del Ebro, Monografías Arqueológicas 28, Zaragoza, 326 págs.

TABAR, I. (1975): “Aportaciones al Paleolítico de Navarra. Yacimientos de Otxaportillo y de la Fuente de Andasarri en la Sierra de Urbasa”, XIII Congreso Nacional de Arqueología (Huelva, 1973): 79-84. (1977): "Nuevas localizaciones paleolíticas en la Sierra de Urbasa. I", PV 148-149: 371-402. (1978): "Nuevas localizaciones paleolíticas en la Sierra de Urbasa. II", $P V$ 150-151: 5-33.

UTRILLA, P. (1984): "El Paleolítico en el curso medio del río Ebro: Calahorra y su entorno", Calahorra. Bimilenario de su Fundación: 11-23. Madrid.

VALLESPÍ, E. (1971): "Novedades del Paleolítico Inferior y Medio Vasco: Los yacimientos navarros de Urbasa y Olazagutía", Actas de la I ${ }^{a}$ Semana Internacional de Antropología Vasca: 565-576. Bilbao.

VALLESPÍ, E. y RUIZ DE GAONA, M. (1971): "Piezas líticas de tradición achelense en las series líticas de Coscobilo de Olazagutía (Navarra)", Munibe 23: 375-384.

VEGA, L.G.; RAPOSO, L. y SANTONJA, M., en: Wil Roebroeks and Clive Gamble (eds.) (1999): The Middle Palaeolithic occupation of Europe: 23-48. University of Leiden. 


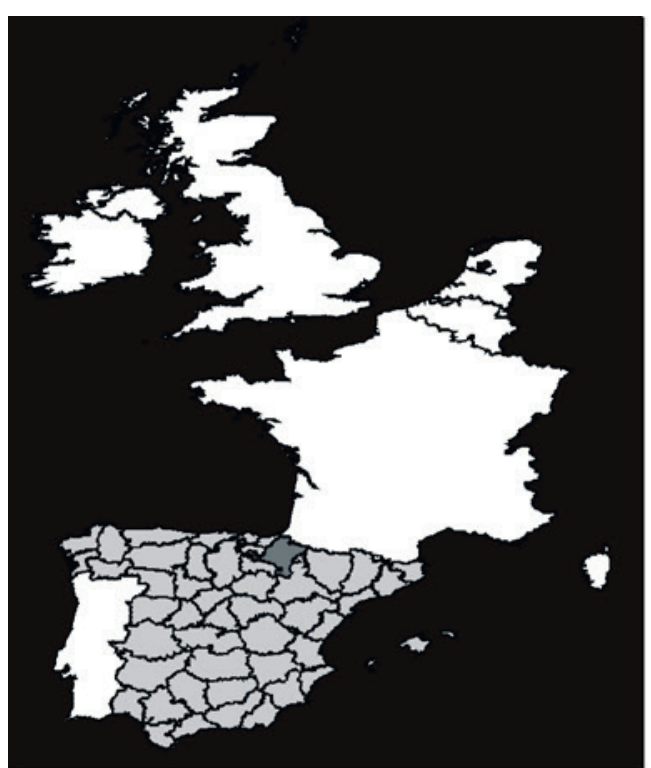

1. Abauntz (Cueva, Valle de Ulzama)

2. Arazuri 1 (Cuenca de Pamplona)

3. Balsa de Aranzaduia (Urbasa)

4. Bioiza (Urbasa)

5. Canteras de Alaiz (Cuenca de Pamplona)

6. Coscobilo (Cueva de Olazagutia, Barranca)

7. Eriete 1 (Cuenca de Pamplona)

8. Fuente de Aciarri (Urbasa)

9. Fuente de Andasarri (Urbasa)

10. Fuente de Gorlasaro (Urbasa)

11. Galar 1 (Cuenca de Pamplona)

12. Gazólaz 4 (Cuenca de Pamplona)

13. Ibero 3 (Cuenca de Pamplona)

14. Ibero 4 (Cuenca de Pamplona)

15. Ibero 5 (Cuenca de Pamplona)

16. Ibero 8 (Cuenca de Pamplona)

17. Mugarduia Norte (Urbasa, publicado inicialmente como Otxaportillo)

18. Olabe (Ulzama)

19. Ororbia 2 (Cuenca de Pamplona)

20. Ororbia 3 (Cuenca de Pamplona)

21. Pozo Laberri (Urbasa)

22. Pozo Negro (Úrbasa)

23. Salinas 1 (Cuenca de Pamplona)

24. Tudela

25. Viana

26. Varios

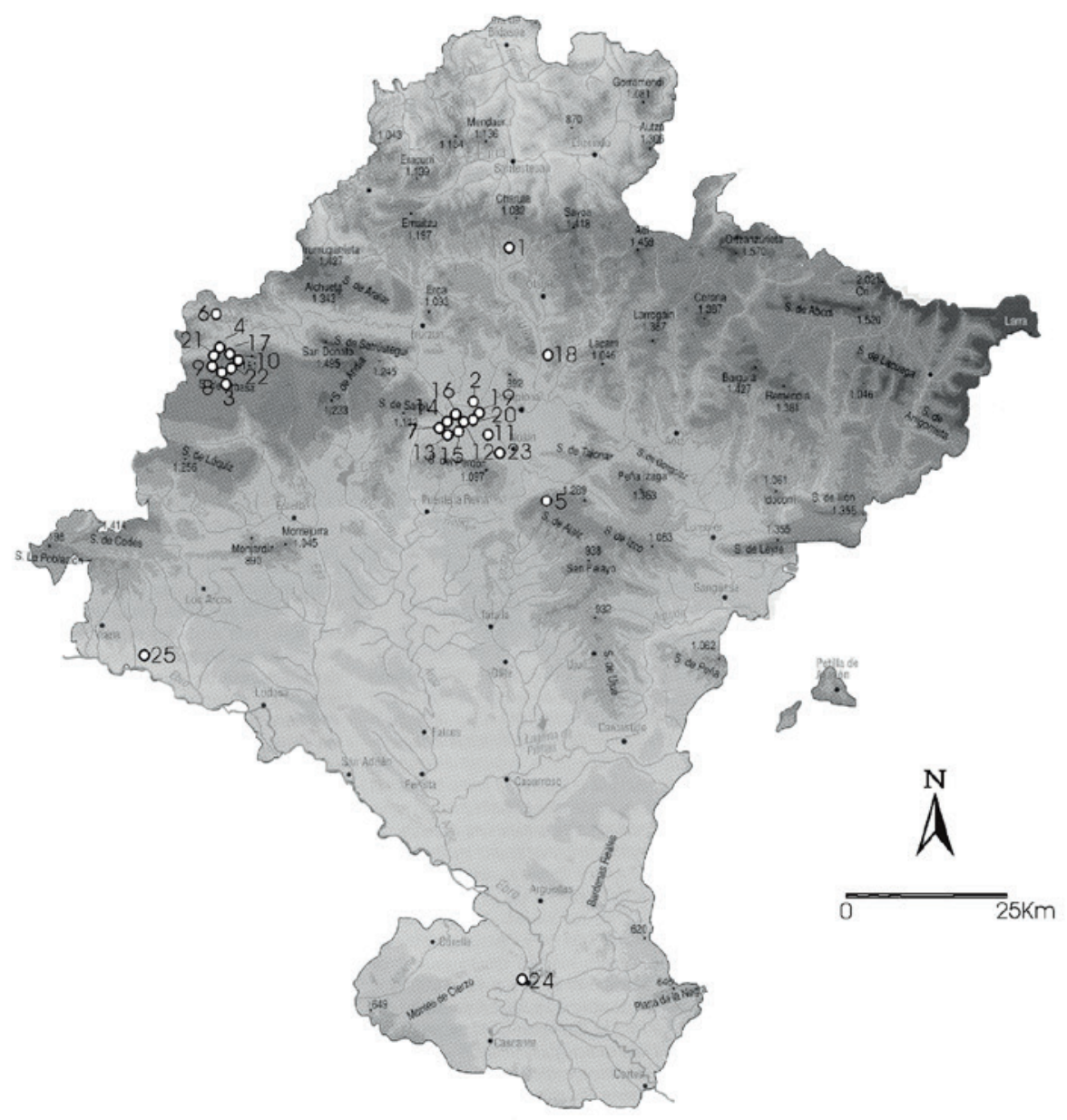

Figura 1. Localización de los yacimientos citados en el texto. 

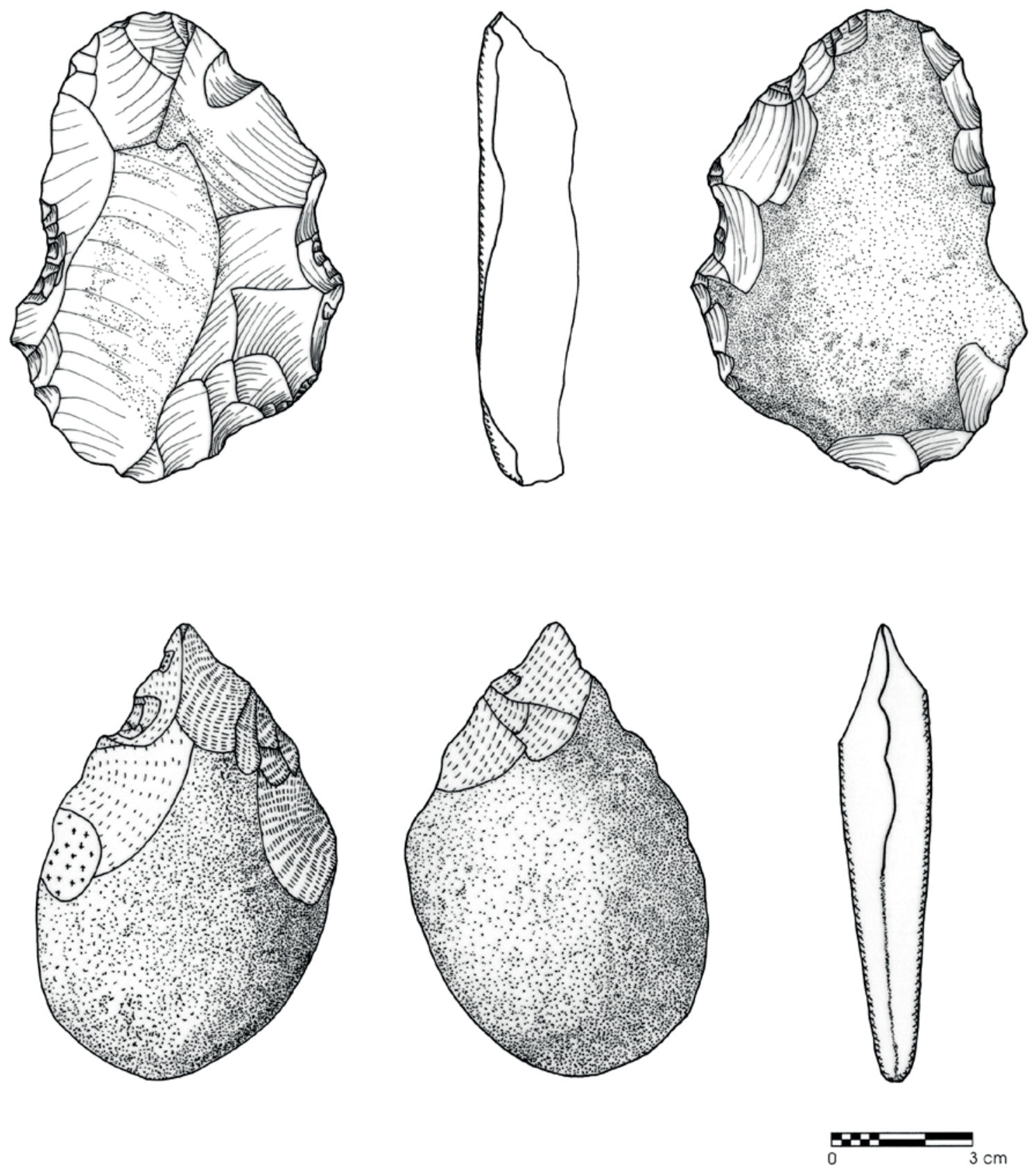

Figura 2. Núcleo de tecnología levallois y triedro de Salinas 1.

ISSN: 1133-4525 ISSN-e: 2255-3924

SPAL 9 (2000)

http://dx.doi.org/10.12795/spal.2000.19.11 

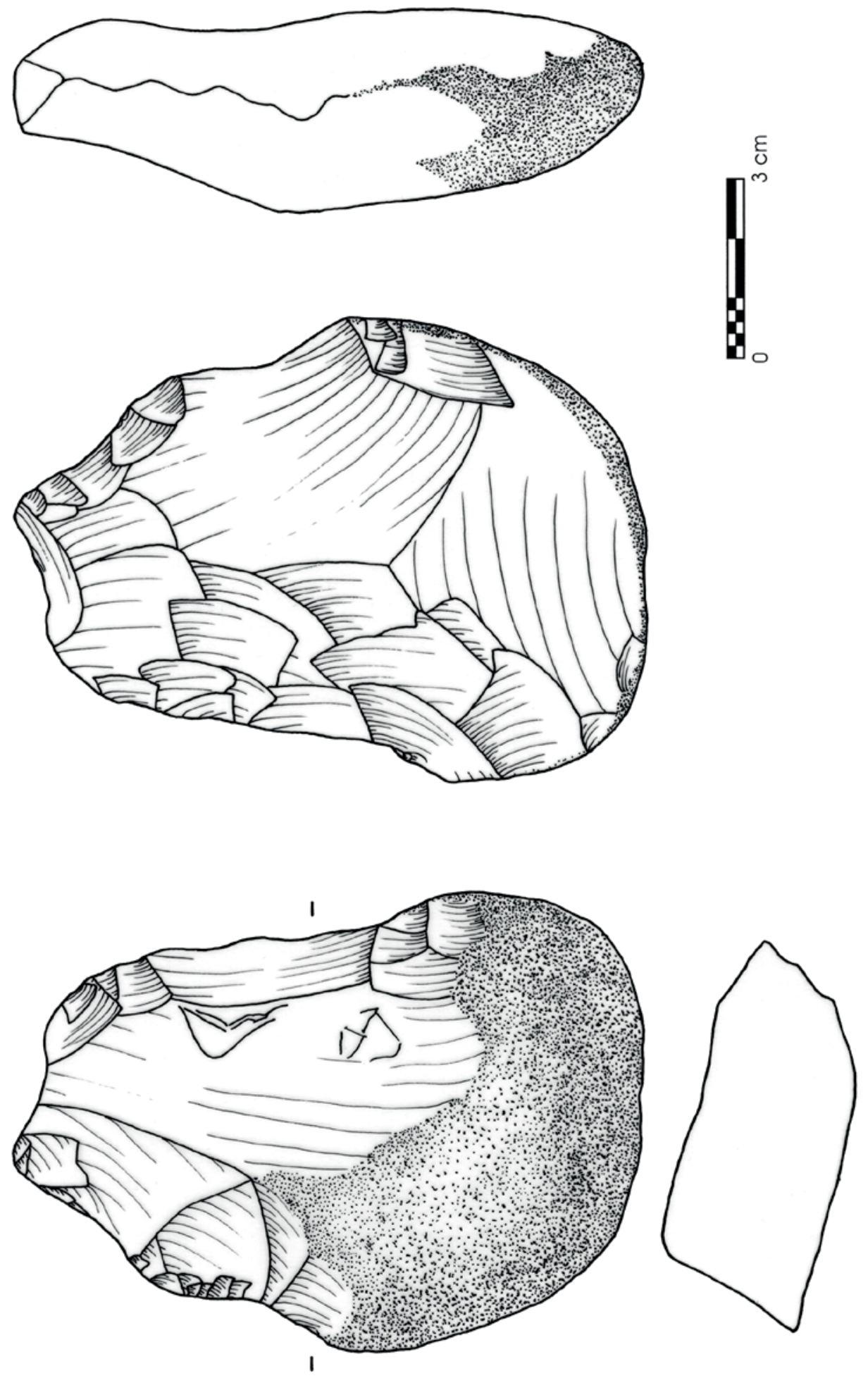

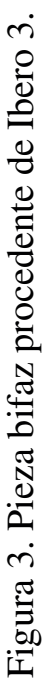



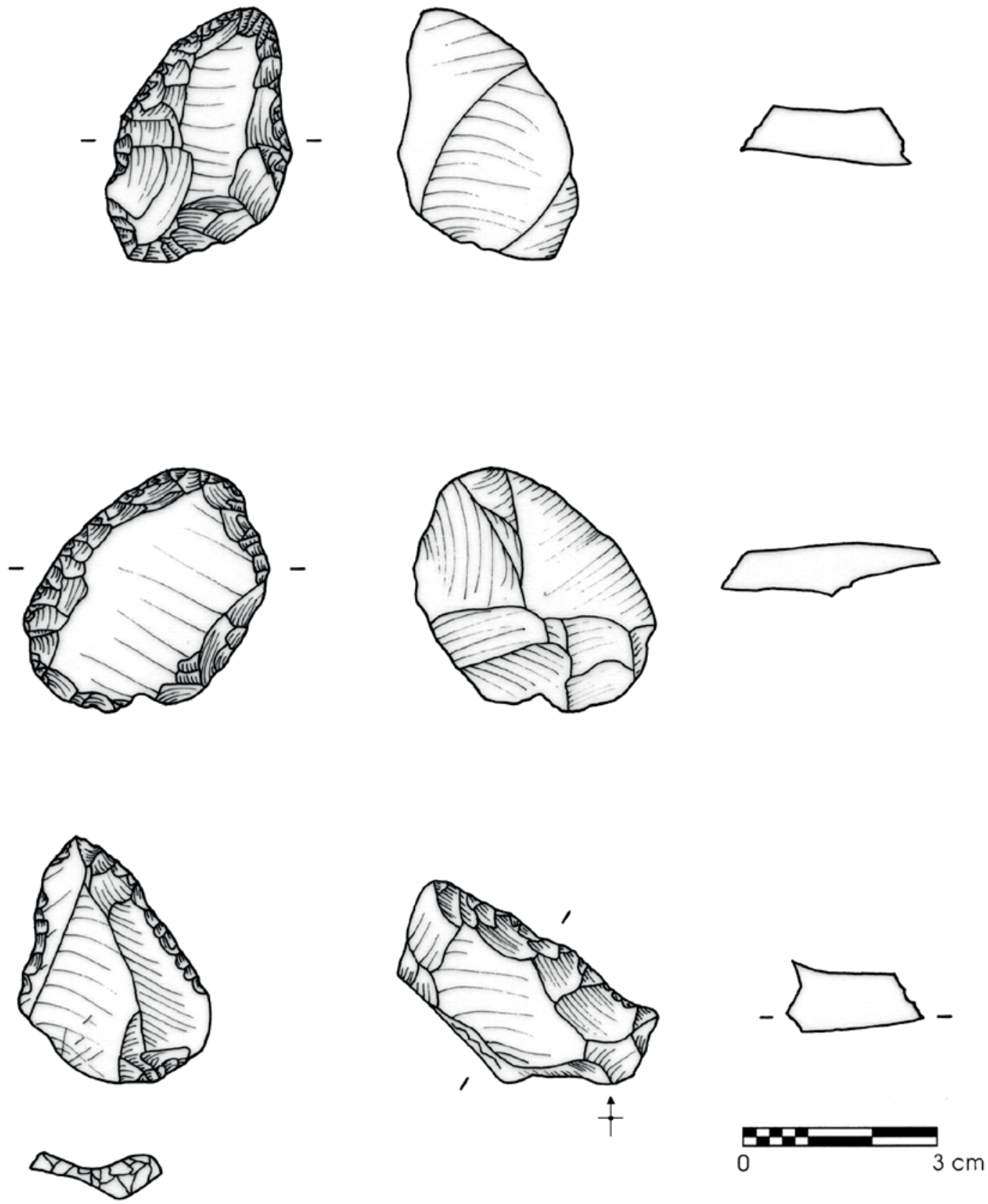

Figura 4. Ibero 4 y 5: raederas y punta levallois retocada.

ISSN: 1133-4525 ISSN-e: 2255-3924

SPAL 9 (2000)

http://dx.doi.org/10.12795/spal.2000.i9.11 

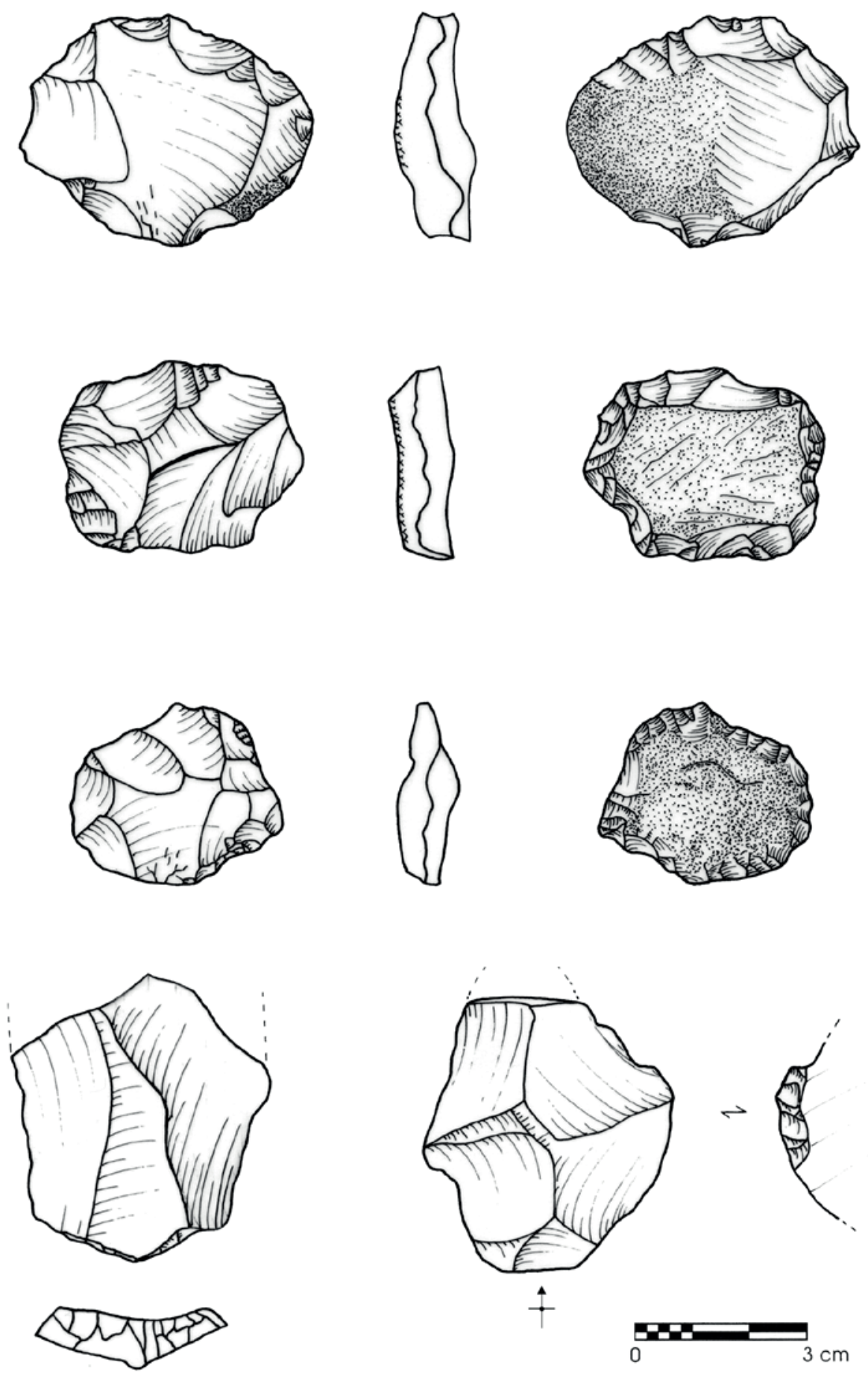

Figura 5. Núcleos y fragmentos de lascas procedentes de Ibero 5. 

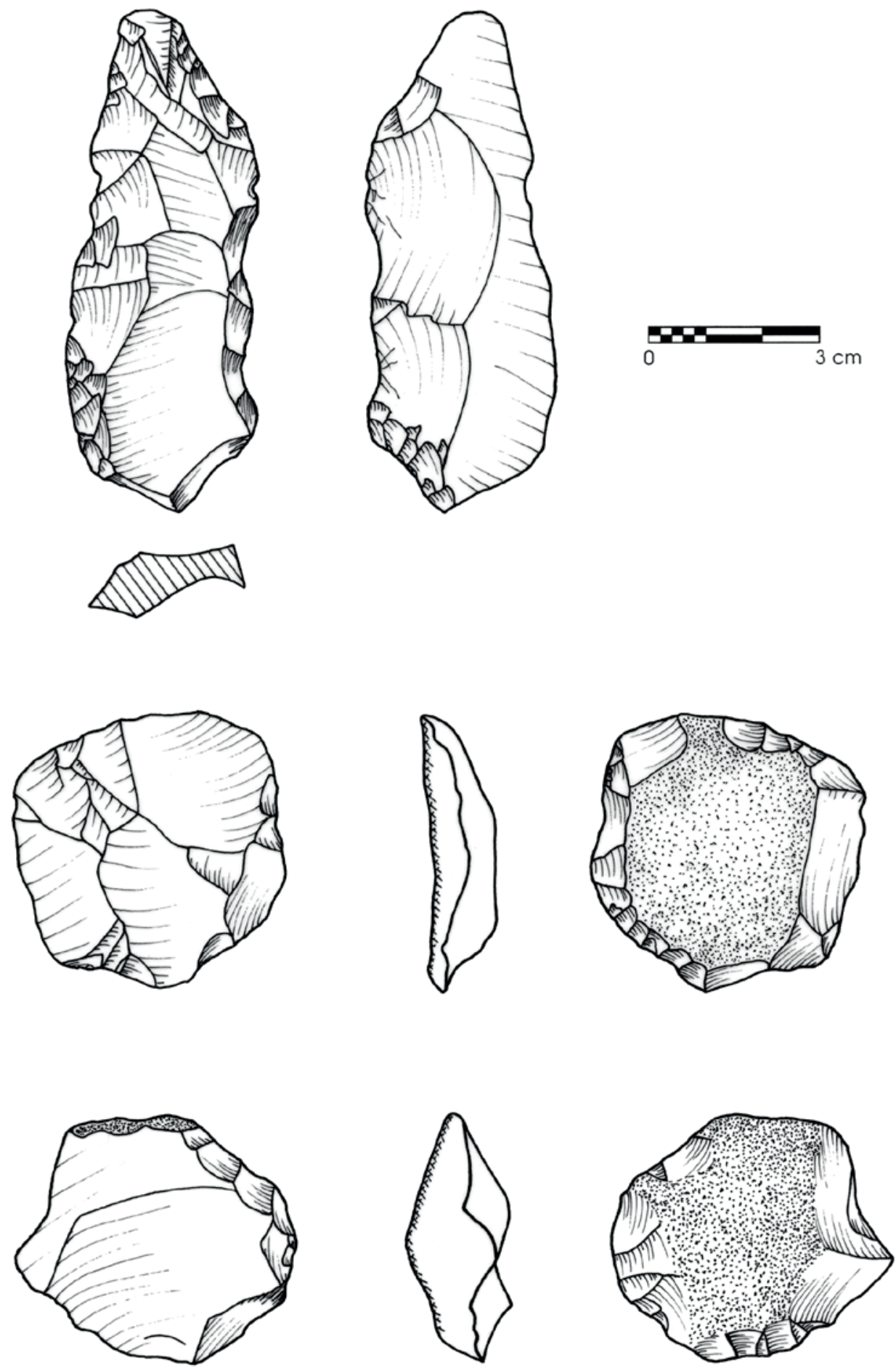

Figura 6. Raedera de dorso adelgazado y núcleos levallois de Ibero 5.

ISSN: 1133-4525 ISSN-e: 2255-3924

SPAL 9 (2000)

http://dx.doi.org/10.12795/spal.2000.19.11 

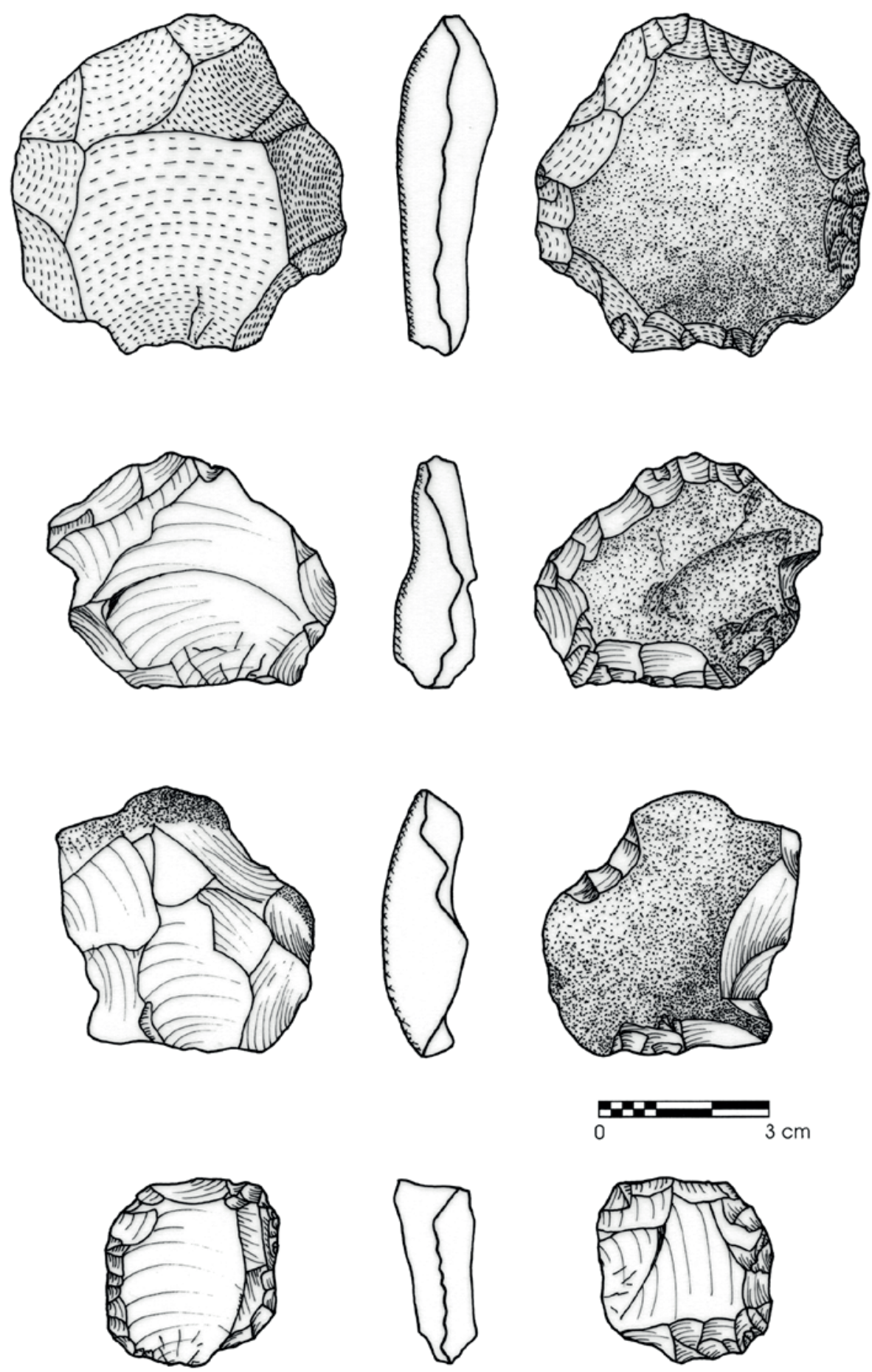

Figura 7. Núcleos y raedera de Ibero 8 . 